\title{
IMAGING OF OPTIC DISC DRUSEN: A COMPARATIVE STUDY
}

\author{
SUNDEEP KHETERPAL ${ }^{1}$, PETER A. GOOD ${ }^{1}$, DAVID J. BEALE ${ }^{2}$ and \\ ERNA E. KRITZINGER ${ }^{1}$ \\ Birmingham and Coventry
}

\begin{abstract}
SUMMARY
The choice of imaging technique to identify the presence of optic disc drusen has not been well established. We performed computed tomography (CT), magnetic resonance imaging (MRI), fundus fluorescein angiography and B-mode ultrasonography (B-USG) on four patients with optic disc drusen as the sole identifiable pathological process. CT, MRI and examination for autofluorescence demonstrated the presence of drusen in only one case each. B-USG showed characteristic features of optic disc drusen in all cases. We suggest that B-USG, a non-invasive and inexpensive technique, may be the imaging method of choice in identifying the presence of disc drusen.
\end{abstract}

Buried drusen of the optic disc are often difficult to distinguish from disc swelling due to other causes such as papilloedema or ischaemic optic papillopathy. Investigations such as fundus fluorescein angiography (FFA), B-mode ultrasonography (B-USG) and computed tomography (CT) are used to examine such patients. No comparative study of these techniques, or of magnetic resonance imaging (MRI), has been reported. We present the investigation results of four patients who underwent neuroophthalmological investigation with FFA, B-USG, CT and MRI. The only demonstrable pathological process found in all patients was optic disc drusen. Only B-USG was able to demonstrate the presence of optic disc drusen in every case. We also present the first magnetic resonance image of optic disc drusen.

\section{METHODS}

Four patients with swollen optic discs underwent neuro-ophthalmological investigation with B-USG, FFA, CT and MRI. Resolution details were as follows:

From: ${ }^{1}$ Birmingham and Midland Eye Hospital, Birmingham, UK: ${ }^{2}$ Walsgrave Hospital, Coventry, UK.

Correspondence to: Dr Sundeep Kheterpal, MA, MRCOphth, Birmingham and Midland Eye Hospital, Church Street, Birmingham B3 2NS, UK.
B mode ultrasonography: Digital B2000; $10 \mathrm{MHz}$ frequency; $0.15 \mathrm{~mm}$ resolution.

Computed tomography: GE 8800 scanner; $1.5 \mathrm{~mm}$ slice thickness; $0.5 \mathrm{~mm}$ in-plane resolution.

Magnetic resonance imaging: Picker $0.5 \mathrm{~T}$ superconducting magnet and surface coil. (1) axial/coronal T1-weighted spin echo images [TR 540, TE 20, FOV $20 \mathrm{~cm}$, matrix $192 \times 200$ ]; $3 \mathrm{~mm}$ slice thickness and 1 $\mathrm{mm}$ in-plane resolution. (2) Axial 3DFT gradient echo T1-weighted images [TR 100, TE 18, FOV 20 $\mathrm{cm}] ; 2 \mathrm{~mm}$ slice thickness and $1 \mathrm{~mm} \times 0.8 \mathrm{~mm}$ inplane resolution.

All patients had optic disc drusen as their primary diagnosis. No invasive investigations were performed for the purpose of the study.

\section{RESULTS}

The results are shown in Table I.

The presence of autofluorescence was demonstrated in only one case (Fig. 1). CT demonstrated characteristic superficial calcification consistent with the presence of drusen in one case also (Fig. 2). MRI, using a high-resolution coil, was able to detect a surface disc transparency in one patient (Fig. 3). BUSG demonstrated high reflectivity characteristic of drusen in all four cases (Fig. 4). No other underlying pathology was found in any patient.

\section{DISCUSSION}

Drusen of the optic disc are deposits of calcium within disrupted optic nerve axonal mitochondria. They were first described clinically in 1868 by Liebrich ${ }^{1}$ and histopathologically by Müller in $1858 .^{2}$ They occur almost exclusively in the Caucasian population with a prevalence of $0.3 \%$. Seventy per cent of drusen are bilateral and may occur as a dominant trait with incomplete penetrance. Associations with retinitis pigmentosa and angioid streaks have been described but no other associated systemic features are known. ${ }^{3}$ Abnormal metabolism is 
Table I. Results of four imaging techniques for the identification of optic disc drusen

\begin{tabular}{|c|c|c|c|c|c|}
\hline Case no. & Referred as & FFA & B-USG & $\mathrm{CT}$ & MRI \\
\hline 1 & Giant cell arteritis? & Disc normal & Drusen & Disc normal & Disc normal \\
\hline 2 & Giant cell arteritis? & Disc normal & Drusen & Disc normal & Disc normal \\
\hline 3 & $\begin{array}{l}\text { Late onset migraine. } \\
\text { ?Intracranial lesion }\end{array}$ & Autofluorescence & Drusen & Disc normal & Drusen \\
\hline 4 & $\begin{array}{l}\text { Recurrent bilateral branch } \\
\text { vein occlusion }\end{array}$ & Disc normal & Drusen & Drusen & Disc normal \\
\hline
\end{tabular}

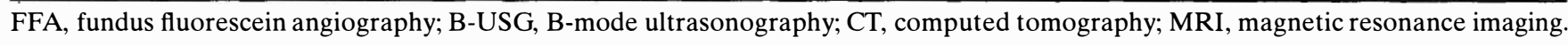

thought to lead to the deposition of calcium within optic nerve axonal mitochondria. The axons are disrupted and mitochondria extruded. Further calcium deposition in these extracellular mitochondrial groups occurs forming drusen which lead to disc swelling. ${ }^{4}$ Up to $87 \%$ of patients with drusen have visual field loss of varying nature. ${ }^{5}$ Superficial, subretinal and intravitreal haemorrhages may also occur. Other complications include vascular occlusion of which ischaemic optic neuropathy is the most common type. ${ }^{6}$

Mustonen et al. ${ }^{7}$ examined the eyes of 180 patients with clinically evident optic disc drusen. Fundus

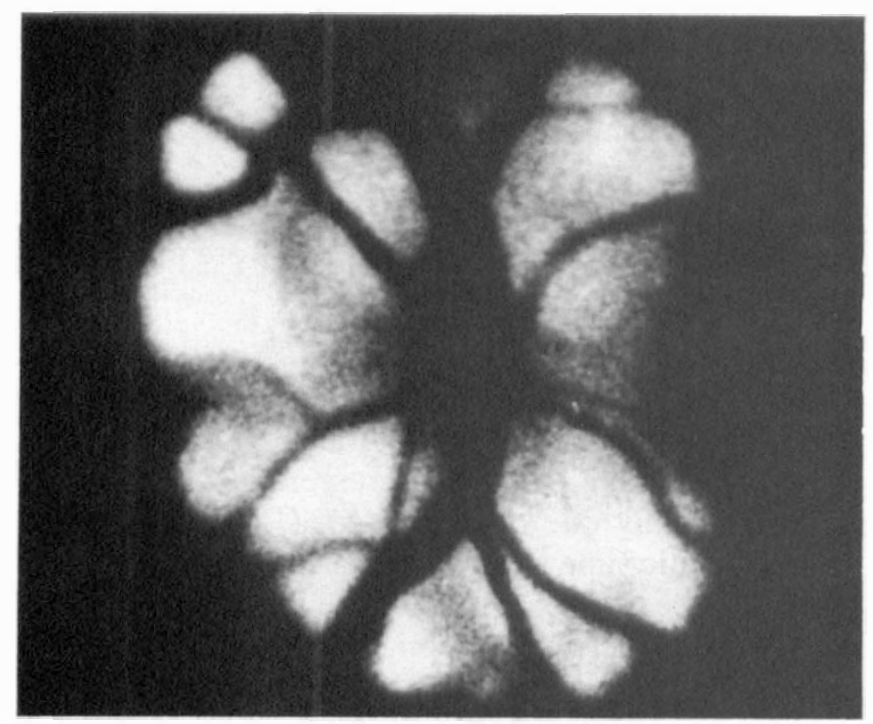

Fig. 1. Optic disc autofluorescence.

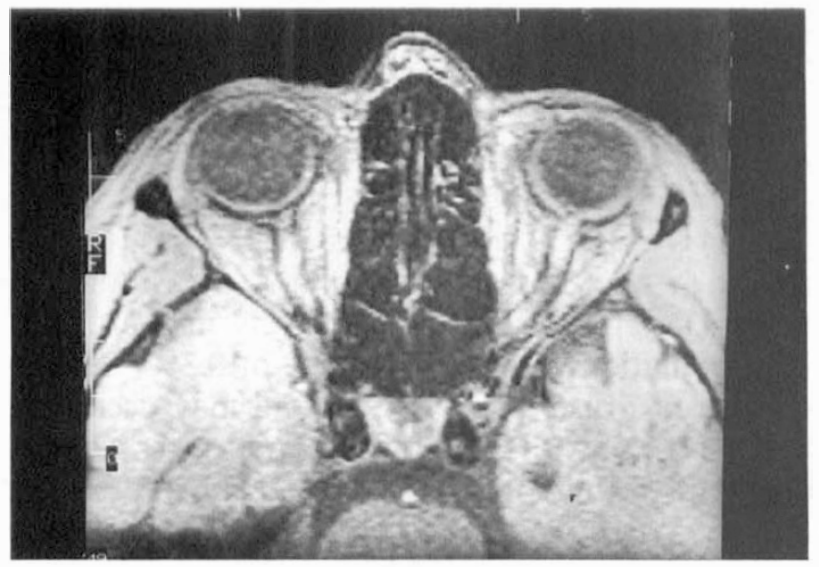

Fig. 3. Magnetic resonance image demonstrating surface disc transparency consistent with calcification. photography demonstrated autofluorescence in 140 $(75 \%)$ cases. Many of the remainder were buried drusen in children. Two forms of autofluorescence were described: an early bright form and a late uptake of fluorescein occurring with buried drusen. ${ }^{7}$ Boldt et al. ${ }^{8}$ found that 39 of $48(81 \%)$ cases of drusen demonstrated with B-USG were visible clinically. B-USG may elicit the presence of drusen in $43 \%$ of patients with optic disc swelling. Frisen $e t$ $a l .{ }^{9}$ examined five patients with high-resolution CT and noted that calcified drusen produced an increased attenuation visible at the optic nerve head. Recent discussion has indicated the possible

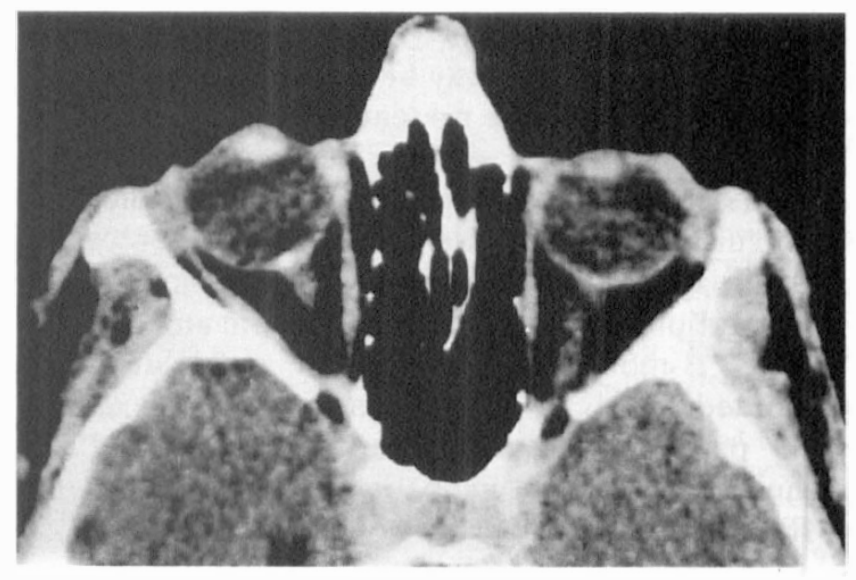

Fig. 2. CT scan demonstrating characteristic superficial calcification consistent with the presence of drusen.

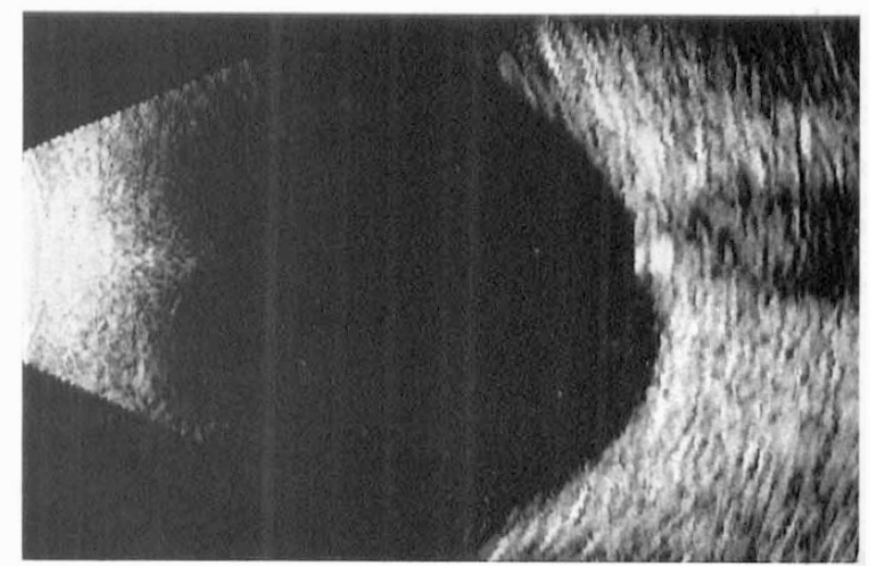

Fig. 4. B-mode ultrasonography demonstrating high reflectivity characteristic of drusen. 
superiority of CT over B-USG in the imaging of drusen. ${ }^{10}$ This first comparative study indicates that B-USG - which is rapid, non-invasive and inexpensive - may be more sensitive than CT. However, further investigation should be undertaken in such patients where there is clinical suspicion that there may be dual pathology. ${ }^{11}$ MRI is expensive, requires special techniques and considerable patient cooperation and is therefore also unlikely to be the first choice of investigation in these patients.

Key words: Autofluorescence, Computed tomography, Drusen, Echography, Magnetic resonance imaging, Ultrasonography.

\section{REFERENCES}

1. Liebrich R. Contribution to discussion on: Iwanoff A, Über neuritis optica. Klin Monatsbl Augenheilkd 1868; 6:426.

2. Müller H. Anatomische Beitrage zur Ophthalmologie: VIII. Graefes Arch Clin Exp Ophthalmol 1858;4:1.

3. Boye SW, Platia EV, Green WR. Drusen of the optic nerve head. Ann Ophthalmol 1978;10:695-704.
4. Tso MO. Pathology and pathogenesis of drusen of the optic nerve head. Ophthalmology 1981;88:1066-80.

5. Cohen D. Drusen of the optic disc and the development of visual field defects. Arch Ophthalmol 1971; 85:224.

6. Harris MJ, Fine SL, Owen SL. Haemorrhagic complications of optic nerve drusen. Am J Ophthalmol 1981;92:70-6.

7. Mustonen E, Nieminen H. Optic disc drusen: a photographic study. I. Autofluorescence pictures and fluorescein angiography. Acta Ophthalmol (Copenh) 1982;60:849-58.

8. Boldt HC, Byrne SF, DiBernado C. Echographic evaluation of optic disc drusen. J Clin Neuro Ophthalmol 1991;11:85-91.

9. Frisen L, Scholdstrom G, Svendsen P. Drusen in the optic nerve head: verification by computerised tomography. Arch Ophthalmol 1978;96:1611-4.

10. Miller NR. Visible drusen in optic discs. Arch Ophthalmol 1986;104:1587-8.

11. Carter JE. Pseudodrusen of the optic disc. J Clin Neuro Ophthalmol 1989:9:273-6. 